\title{
(6) \\ Support for e-cigarette policies: a survey of smokers and ex-smokers in Great Britain
} OPEN ACCESS

\author{
Leonie S Brose, Timea R Partos, Sara C Hitchman, Ann McNeill
}

\begin{abstract}
- Additional material is published online only. To view please visit the journal online (http://dx.doi.org/10.1136/ tobaccocontrol-2016-052987).

Department of Addictions, Institute of Psychiatry, Psychology and Neuroscience, King's College London, UK and UK Centre for Tobacco and Alcohol Studies (UKCTAS), London, UK
\end{abstract}

\section{Correspondence to} Dr Leonie S Brose, Department of Addictions, Institute of Psychiatry, Psychology and Neuroscience, King's College London, 4 Windsor Walk, London SE5 8BB, UK; leonie.brose@kcl.ac.uk

Received 12 February 2016 Revised 18 May 2016 Accepted 24 May 2016 Published Online First 16 June 2016

\section{CrossMark}

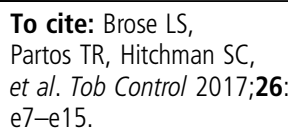

\section{ABSTRACT}

Introduction E-cigarette regulations are the topic of extensive debate. Approaches vary worldwide, and limited evidence is available on public support for specific policies or what influences support. The present study aimed to assess smokers' and ex-smokers' support for 3 e-cigarette policies: (1) equal or higher availability relative to cigarettes, (2) advertising, (3) use in smokefree places, and to assess changes in support over time and associations with respondent characteristics.

Methods Smokers and ex-smokers $(n=1848)$ provided 3279 observations over 2 waves (2013 and 2014) of a longitudinal web-based survey in Great Britain.

Multivariable logistic regressions fitted using generalised estimating equations assessed change in policy support over time, and associations between support and demographics (age, gender and income), smoking and e-cigarette use status, nicotine knowledge and perceived relative harm.

Results Equal or higher relative availability was supported by $79 \%$ in 2013 and $76 \%$ in 2014 ; advertising by $66 \%$ and $56 \%$, respectively; neither change was significant in adjusted analyses. Support for use in smoke-free places decreased significantly from $55 \%$ to $45 \%$. Compared with ex-smokers, smokers were more likely to support advertising and use in smoke-free places. Respondents using e-cigarettes, those who perceived e-cigarettes as less harmful than cigarettes, and those with more accurate knowledge about nicotine were more likely to support all 3 policies.

Conclusions Less restrictive e-cigarette policies were more likely to be supported by e-cigarette users, and respondents who perceived e-cigarettes to be less harmful than cigarettes, or knew that nicotine was not a main cause of harm to health.

\section{INTRODUCTION}

E-cigarettes use battery power to heat a solution of propylene glycol or glycerine, water, flavouring and often nicotine, resulting in an aerosol that can be inhaled by the user (commonly termed vapour). In contrast with traditional cigarettes, e-cigarettes do not contain tobacco, do not create smoke and do not rely on combustion. ${ }^{1}$ Although the main reason for addiction to smoking is nicotine, the health harms of smoking are caused by other constituents of cigarette smoke. ${ }^{23}$

Appropriate regulation of e-cigarettes is the topic of extensive debate, and approaches vary across countries. ${ }^{4}$ To date, it is not yet clear as to which e-cigarette policies will lead to desirable public health outcomes such as decreased harm from smoking. In traditional tobacco control, public support has been an important component in getting policies adopted in law. ${ }^{5}$ As there is much debate around the evidence base regarding ecigarettes, it is important to understand people's views and the correlates of policy support. Three key domains of e-cigarette regulations are now discussed.

\section{Availability}

A recent review of global approaches to regulation found that 21 countries restricted the sale of e-cigarettes with nicotine and 26 countries banned sale of all types of e-cigarettes. ${ }^{4}$ E-cigarettes are widely available in the UK; manufacturers may apply for medicinal licensing, ${ }^{6}$ or sell their e-cigarettes as unlicensed products under general product safety regulations, and from May 2016 under the revised European Union Tobacco Products Directive (TPD). ${ }^{7}$ In the UK, the Royal Society for Public Health has called for making ecigarettes and other nicotine-containing products more widely available than combustible tobacco products. ${ }^{8}$ Their rationale was that making less harmful nicotine sources more easily available than cigarettes may encourage smokers to quit smoking and help those trying to quit smoking to overcome cravings. ${ }^{8}$ To date, there is no published evidence from the UK or elsewhere, on public preferences for availability of e-cigarettes.

\section{Advertising}

The majority of countries that ban or restrict sale of e-cigarettes also prohibit or restrict advertising, promotion or sponsorship. ${ }^{4}$ In the European Union, from 2016, the TPD will lead to prohibition of advertising on broadcast and on demand $\mathrm{TV}$, radio, print magazines and newspapers, internet, email, text message, sponsorship of activity or individuals with cross-border effects. ${ }^{9}$ In the UK, current rules stipulate that e-cigarette advertising must not cross-promote tobacco brands, promote tobacco products and must make clear that the product is not a tobacco product. ${ }^{10}$ Advertising also must not be likely to appeal particularly to people under 18 years, nor show people who are or look under 25 years using e-cigarettes or playing a significant role. ${ }^{10}{ }^{11}$ Two surveys, both in the USA, have assessed aspects of support for advertising regulations. ${ }^{12} 13$ One found lower support for advertising restrictions among smokers who had tried or used e-cigarettes, and smokers who believed e-cigarettes to be less harmful than cigarettes in unadjusted analyses; ${ }^{12}$ the other found universally high support for banning advertising e-cigarettes to youth under 18 years. ${ }^{13}$ 


\section{Use in smoke-free places}

Policies banning tobacco smoking, for example, in public places or workplaces are based on the evidence that secondhand smoke exposure in enclosed public spaces is harmful to health. $^{14}{ }^{15}$ There is little evidence that e-cigarette vapour/ aerosol causes harm to the health of bystanders. ${ }^{1}$ Evidence does suggest that e-cigarette use increases the concentration of fine particulate matter suspended in air. ${ }^{16} 17$ However, the composition of the particulate matter is different from cigarette smoke, ${ }^{18}$ and concentrations are far lower than those caused by cigarette smoke, ${ }^{19}$ and not always distinguishable from those in non-smoking and non-vaping environments. ${ }^{20} \mathrm{~A}$ small number of countries ban all use of e-cigarettes, some ban use in certain or all enclosed public spaces, others specifically prohibit use on public transportation. ${ }^{4}$ However, policies can also vary within countries. For example, in the UK, one of the four member countries has consulted on banning e-cigarette use in public places, ${ }^{21}$ while the other three UK countries do not have any plans to do so. Similarly, regulations differ between individual states within other countries, for example, in the USA or Australia. Often, policies are determined at a local level by local governments, companies or institutions, resulting in varying approaches. $^{22-24}$ Previous surveys, one from Spain, the others from the USA, have assessed support for restrictions on use of ecigarettes in enclosed public places or areas where smoking is not allowed. ${ }^{12} 13 \quad 25-29$ They generally found that those who had used or tried e-cigarettes, as well as smokers, were less supportive of restrictions. Perceiving e-cigarettes as less harmful than smoking was also associated with being less supportive of restrictions, ${ }^{12}$ while perceived harmfulness of breathing secondhand vapour ${ }^{26} 27$ and perceived addictiveness of e-cigarettes ${ }^{26}$ were associated with higher support for restrictions.

\section{Aims}

The present study aimed to answer the following research question: in a cohort of smokers and ex-smokers, how did support for different e-cigarette policies change over time, and how did it vary with sociodemographic characteristics, e-cigarette use, smoking status, perceived relative harm of e-cigarettes, and knowledge about what portion of health harms of smoking comes from nicotine? Support was assessed for policies on ecigarette availability, advertising and use in smoke-free places in 2013 and 2014.

\section{METHODS}

\section{Design and sample}

We used data from a longitudinal web-based survey of a general population sample of smokers and ex-smokers (ex-smokers had quit smoking during the year before the baseline wave) in Great Britain. Members of an online panel managed by Ipsos MORI were invited to participate in a survey about smoking. Members of the panel consent to complete surveys, and for each completed survey earn points which can be redeemed against shopping vouchers or used to enter a prize draw. Those who accepted the invitation $(n=23785)$ were screened, and past-year smokers $(n=6165)$ were eligible for the survey. Quotas were imposed to ensure broad representativeness of the British population by gender, age and region at recruitment. Baseline/wave 1 (November/December 2012) was completed by 5000 respondents. The cohort data have previously been used to show that changes in smoking behaviour vary with the frequency of ecigarette use ${ }^{30}$ and the type of device used, ${ }^{31}$ and to demonstrate an increase in the perceived harm of e-cigarettes relative to cigarettes over time. ${ }^{32}$ The present analyses include data from wave 2 in 2013 and wave 3 in 2014, when policy questions were added to the survey. In 2013, 2182 respondents completed the survey $(43.6 \%$ of wave 1$) ; n=93$ not aware of e-cigarettes were not asked about e-cigarette policies, and $n=198$ ex-smokers who had quit smoking more than 1 year ago were erroneously not asked about e-cigarette policies. Wave 3 was completed by 1519 respondents (69.6\% of wave 2), of whom $\mathrm{n}=42$ not aware of e-cigarettes were not asked about e-cigarette policies. Respondents who did not know or disclose key information (other than income) were excluded $(n=43)$, leaving $\mathrm{n}=1848$ respondents who provided 3279 observations.

\section{Measures}

\section{Demographics}

Demographics at wave 2 (2013) were used for analyses. They included age (for analysis, grouped as $18-24$ years; $25-39$ years; 40-54 years; 55 years and over) and gender (male and female). The analyses included annual non-equivalised household income (Under £6500; £6500-15 000; £15 001-30 000; $£ 30$ 001-40 000; £40 001-50 000; £50 001-65 000; £65 00195 000; $£ 95001$ and over; 'Don't know'; 'Prefer not to say’). The UK government defines 'low income' to be $40 \%$ below the national median income. In 2013/2014, this threshold was just over $£ 14000,{ }^{33}$ which is why responses were collapsed into 'up to $£ 15000$ ' (low income), ‘ $£ 15001$ to $£ 30000$ ' (middle income) and 'over $£ 30000$ ' (higher income); owing to a considerable proportion of respondents selecting 'don't know' or 'prefer not to say', these responses were kept as an additional category. Since income could not be equivalised by household size, sensitivity analyses were also run using highest level of education (dichotomised into 'no higher education' and 'higher education') in its place.

\section{E-cigarette use and smoking status}

E-cigarette use status at each wave was derived from two questions: (1) 'Have you ever tried an electronic cigarette? (a) Yes; (b) No; (c) Don't know' and (2) 'How often, if at all, do you currently use an electronic cigarette? (a) Daily; (b) Less than daily, but at least once a week; (c) Less than weekly, but at least once a month; (d) Less than monthly; (e) Not at all; (f) Don't know'. Responses were combined to derive the following categories: Never tried (1b); tried, but not currently using (1a in combination with $2 \mathrm{e}$ ); current non-daily use (1a in combination with $2 \mathrm{~b}, 2 \mathrm{c}$ or $2 \mathrm{~d}$ ); current daily use (1a in combination with 2a). A small number of don't know responses were excluded (table 1). Smoking status was determined using the question: 'Which of the following best applies to you? (a) I smoke cigarettes (including hand rolled) everyday; (b) I smoke cigarettes (including hand rolled) but not every day; (c) I do not smoke cigarettes at all but I do smoke tobacco of some kind (eg, pipe or cigar); (d) I have stopped smoking completely in the last year; (e) I stopped smoking more than a year ago; (f) Don't know/couldn't say'. ${ }^{34}$ For analysis, responses were collapsed into current smoker $(\mathrm{a}-\mathrm{c})$ or ex-smoker $(\mathrm{d}, \mathrm{e})$; (f) was excluded.

\section{Nicotine knowledge and relative harm}

Nicotine knowledge was measured at waves 2 and 3 by asking: 'According to what you know or believe, what portion of the health risks of smoking comes from nicotine in cigarettes? (a) None or very small; (b) Some but well under half the risk; (c) Around half the risk; (d) Much more than half the risk; (e) Nearly all the risk; (f) Don't know'. Perceived relative harm was measured at waves 2 and 3 asking: 'Do you think electronic 
Table 1 Sample, longitudinal survey

\begin{tabular}{|c|c|c|c|c|c|}
\hline & \multicolumn{2}{|l|}{$\begin{array}{l}2013 \\
n=1848\end{array}$} & \multicolumn{2}{|l|}{$\begin{array}{l}2014 \\
n=1431\end{array}$} & \multirow[b]{2}{*}{ Comparison } \\
\hline & Frequency & Per cent & Frequency & Per cent & \\
\hline Gender & & & & & $\chi^{2}=0.69, p=0.41$ \\
\hline Male & 1084 & 58.7 & 860 & 60.1 & \\
\hline Female & 764 & 41.3 & 571 & 39.9 & \\
\hline Age (years) & & & & & $\chi^{2}=14.19, p=0.003$ \\
\hline $18-24$ & 139 & 7.5 & 86 & 6.0 & \\
\hline $25-39$ & 471 & 25.5 & 314 & 21.9 & \\
\hline $40-54$ & 594 & 32.1 & 450 & 31.4 & \\
\hline 55 and over & 644 & 34.8 & 581 & 40.6 & \\
\hline Annual income & & & & & $\chi^{2}=0.07, p>0.99$ \\
\hline Up to $\mathrm{f} 15000$ (low) & 441 & 23.9 & 339 & 23.7 & \\
\hline f15 001-f30 000 (middle) & 572 & 31.0 & 439 & 30.7 & \\
\hline Over f30 000 (high) & 649 & 35.1 & 508 & 35.5 & \\
\hline Don't know/prefer not to say & 186 & 10.1 & 145 & 10.1 & \\
\hline Smoking status & & & & & $\chi^{2}=80.37, p<0.001$ \\
\hline Ex-smoker & 247 & 13.4 & 368 & 25.7 & \\
\hline Current smoker & 1601 & 86.6 & 1063 & 74.3 & \\
\hline E-cigarette use status & & & & & $\chi^{2}=7.29, p=0.06$ \\
\hline Never tried & 781 & 42.3 & 593 & 41.4 & \\
\hline Tried, not using & 385 & 20.8 & 342 & 23.9 & \\
\hline Less than daily use & 448 & 24.2 & 303 & 21.2 & \\
\hline Daily use & 234 & 12.7 & 193 & 13.5 & \\
\hline Health risks of smoking from nicotine & & & & & $\chi^{2}=3.65, p=0.60$ \\
\hline None or very small & 212 & 11.5 & 156 & 10.9 & \\
\hline Some but well under half the risk & 452 & 24.5 & 378 & 26.4 & \\
\hline Around half the risk & 393 & 21.3 & 314 & 21.9 & \\
\hline Much more than half the risk & 359 & 19.4 & 280 & 19.6 & \\
\hline Nearly all the risk & 231 & 12.5 & 168 & 11.7 & \\
\hline Don't know & 201 & 10.9 & 135 & 9.4 & \\
\hline Relative harm of e-cigarettes & & & & & $\chi^{2}=39.13, p<0.001$ \\
\hline More harmful than cigarettes & 38 & 2.1 & 32 & 2.2 & \\
\hline Equally harmful & 199 & 10.8 & 263 & 18.4 & \\
\hline Less harmful than cigarettes & 1199 & 64.9 & 843 & 58.9 & \\
\hline Don't know & 412 & 22.3 & 293 & 20.5 & \\
\hline
\end{tabular}

cigarettes are more harmful than regular cigarettes, less harmful, or are they equally harmful to health? (a) More harmful than regular cigarettes; (b) Equally harmful; (c) Less harmful than regular cigarettes; (d) Don't know'. For analysis, the response options were dichotomised into less harmful (c) and all other, inaccurate, responses $(a, b, d)$.

\section{Policy support}

Availability: 'Do you think that electronic cigarettes should be: (a) As freely available and accessible as traditional cigarettes; (b) More available than traditional cigarettes; (c) Less available than traditional cigarettes; (d) Don't know'. For logistic regressions, these were collapsed into equal or higher availability relative to cigarettes $(a, b)$ and all other responses $(c, d)$.

Advertising: 'Do you think that electronic cigarettes companies should be allowed to advertise e-cigarettes? (a) No, they should not be allowed to advertise electronic cigarettes (similar to traditional cigarettes); (b) Yes, they should be allowed to advertise electronic cigarettes, but not in a way that could attract children; (c) Yes, they should be allowed to advertise electronic cigarettes with no restrictions; (d) Don't know'. For logistic regressions, these were collapsed into 'yes, should be allowed' (b, c) vs should not be allowed/don't know (a, d).
Use in smoke-free places: 'Do you think that people should be allowed to use electronic cigarettes in places where smoking is not allowed? (a) Yes; (b) No; (c) Don't know'; for logistic regressions, (b) and (c) were combined.

\section{Analysis}

Changes in the composition of the sample from 2013 to 2014 were assessed using $\chi^{2}$ statistics. Taking into consideration the correlated nature of the data within respondents across survey waves, we used logistic regressions fitted using the generalised estimating equations approach to compute parameter estimates using an unstructured within-subject correlation structure which makes no assumption about the magnitude of the correlation between pairs of observations. We assessed the association between e-cigarette use status, smoking status, nicotine knowledge, relative harm, age, gender and annual income, and support for each of the three policies. In a first step, bivariate associations between each variable and policy were estimated; a second step estimated associations while adjusting for all other variables and included interactions between time-invariant demographics and wave. Sensitivity analyses replaced income with education. Education did not have a significant association with any of the outcomes, and did not substantively alter the 
associations between the outcomes and other predictors, so only the results using income will be presented here. All analyses were conducted using SPSS V.22.0.

\section{RESULTS}

\section{Sample and attrition}

The sample included at each wave is described in table 1 . The sample contained more men than women, a small proportion of young respondents, and almost a quarter on a low income; 63\% had no higher education. The majority were smokers, and over a third of the sample was using e-cigarettes less than daily or daily. Only around 1 in 10 respondents knew that a very small portion of the health risks of smoking come from nicotine in smoke; a similar proportion thought that nearly all the health risks were caused by nicotine. A small majority perceived ecigarettes to be less harmful than cigarettes. The sample in 2014 contained a higher proportion of ex-smokers than the 2013 sample, and had lost a higher proportion of younger respondents (mean age increased by about 2 years, so the change in the proportion in different age brackets is not fully explained by ageing).

\section{Policy support}

Availability

Support for e-cigarettes being equally or more available than cigarettes decreased slightly over time from $78.8 \%$ in 2013 to $75.9 \%$ in 2014 (figure 1 and table 2), but this change was not significant in adjusted analysis. Only around $5 \%$ of respondents thought e-cigarettes should be less available than traditional cigarettes, with the remainder (16\% and 18\%, respectively) being undecided. Very similar proportions of ex-smokers and smokers thought that e-cigarettes should be equally or more available than cigarettes. Non-daily and daily e-cigarette users were more likely to support equal or higher availability than those who had never tried e-cigarettes in adjusted analysis. Compared with those who thought that nearly all the health risks of smoking came from nicotine, all other respondents were more likely to support equal or higher availability except for those who did not know what portion of risk was due to nicotine-this group was less likely to support equal or higher availability. Those who perceived e-cigarettes to be less harmful than cigarettes were far more likely to support equal or higher availability. Only in unadjusted analysis were those with a high income more likely, and those who did not disclose their income less likely to support equal or higher availability than those with a low income; age and gender were not associated with support (table 2). There was a significant interaction between gender and survey wave, suggesting that women were more likely to change from supporting to not supporting availability between waves than men (see online supplementary table S1).

\section{Advertising}

Support for allowing advertising was significantly lower in 2014 $(55.9 \%)$ than in $2013(66.0 \%)$ in the unadjusted analysis (figure 1 and table 3), but this change was no longer significant in the adjusted analysis (table 3). Most of those supporting advertising thought that advertising should be allowed, but in a way that would not attract children. In 2013, 20.6\% and in 2014, 30.9\% supported no restrictions on e-cigarette advertising, and at both waves, about $13 \%$ responded 'don't know' (figure 1). Compared with ex-smokers, smokers were more likely to respond that advertising should be allowed. The more experience respondents had with e-cigarettes, the higher the

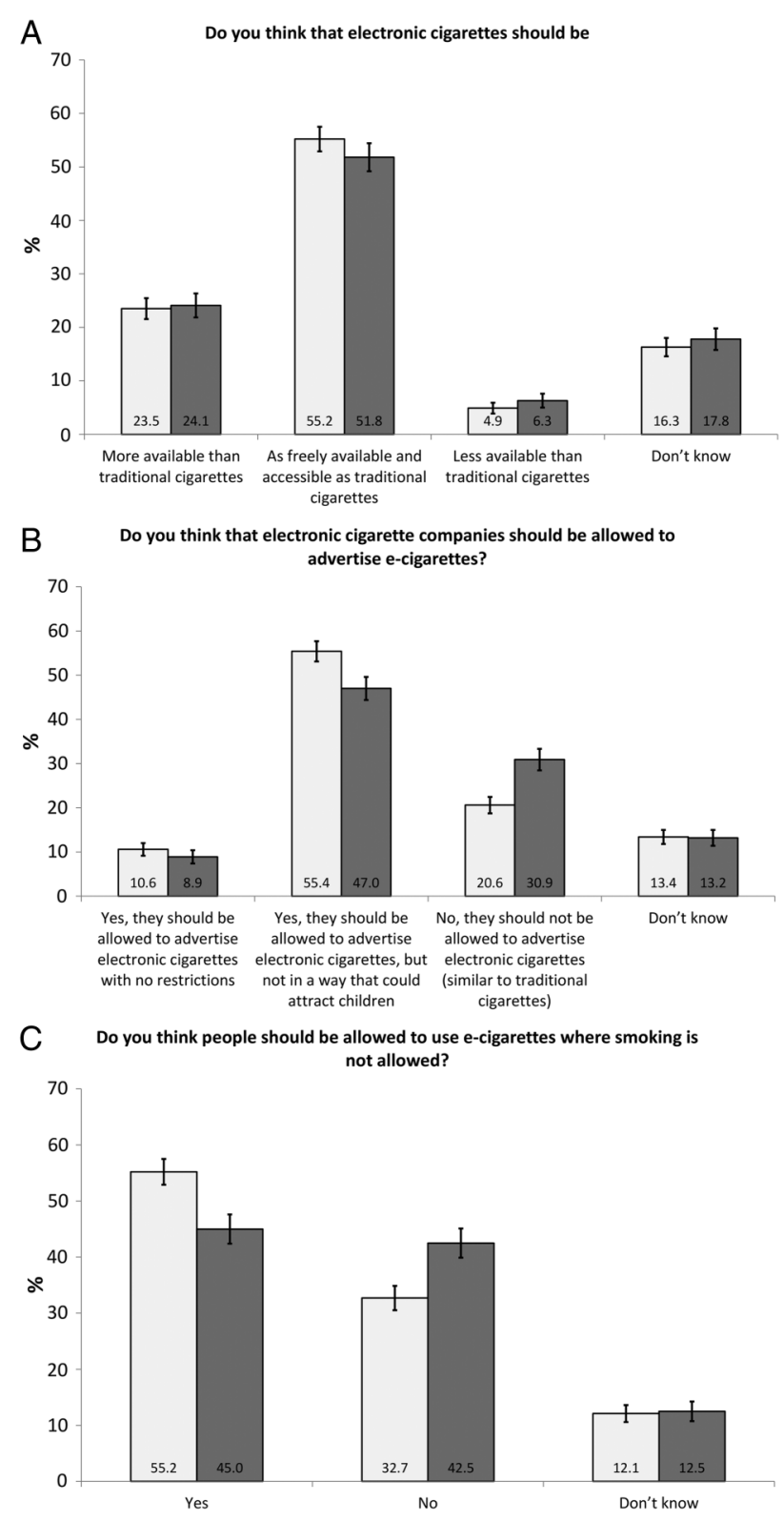

Figure 1 Support for regulations on (A) e-cigarette availability, (B) advertising and (C) use in smoke-free places. (2013: $n=1848 ; 2014$ : $n=1431)$.

odds that they responded that advertising should be allowed. Compared with those who thought that nearly all the health risks of smoking came from nicotine, those who responded that it was none or a very small part, or well under half the risk (in adjusted analysis also those who responded 'much more than half the risk'), were more likely to think that advertising should be allowed. Respondents perceiving e-cigarettes as less harmful than cigarettes were also more likely to support advertising. Age, gender and income were not associated with support (table 3). There were no significant interactions between demographics and survey wave suggesting that these associations did not change over time (see online supplementary table S1).

Use in smoke-free places

Support for use in smoke-free places was overall lower in 2014 (45.0\%) than in 2013 (55.2\%, figure 1 and table 4), and this remained significant in adjusted analyses. About $12 \%$ did not 
Table 2 Association between respondent characteristics and support for availability of e-cigarettes relative to regular cigarettes

\begin{tabular}{|c|c|c|c|c|c|c|c|c|c|}
\hline & \multirow[b]{2}{*}{$\begin{array}{l}\text { Should be equally or } \\
\text { more available (\%) }\end{array}$} & \multicolumn{4}{|c|}{ Bivariate } & \multicolumn{4}{|c|}{ Adjusted/Multivariable } \\
\hline & & OR & $95 \% \mathrm{LCl}$ & $95 \%$ UCI & p Value & OR & $95 \% \mathrm{LCl}$ & $95 \%$ UCI & p Value \\
\hline \multicolumn{10}{|l|}{ Wave } \\
\hline 2013 (referent) & 78.8 & 1.00 & ref & ref & ref & 1.00 & ref & ref & ref \\
\hline 2014 & 75.9 & 0.85 & 0.74 & 0.98 & 0.024 & 1.07 & 0.50 & 2.27 & 0.86 \\
\hline \multicolumn{10}{|l|}{ Smoking status } \\
\hline Ex-smoker (referent) & 76.9 & 1.00 & ref & ref & ref & 1.00 & ref & ref & ref \\
\hline Current smoker & 77.7 & 1.02 & 0.82 & 1.27 & 0.85 & 1.10 & 0.87 & 1.41 & 0.43 \\
\hline E-cigarette & & & & & $<0.001$ & & & & $<0.001$ \\
\hline Never tried (referent) & 70.5 & 1.00 & ref & ref & ref & 1.00 & ref & ref & ref \\
\hline Tried, not using & 75.9 & 1.28 & 1.04 & 1.58 & 0.021 & 1.08 & 0.86 & 1.35 & 0.52 \\
\hline Non-daily use & 83.9 & 2.08 & 1.65 & 2.61 & $<0.001$ & 1.41 & 1.08 & 1.84 & 0.011 \\
\hline Daily use & 91.8 & 4.61 & 3.22 & 6.58 & $<0.001$ & 2.56 & 1.78 & 3.96 & $<0.001$ \\
\hline Risks of smoking from nicotine & & & & & $<0.001$ & & & & $<0.001$ \\
\hline Nearly all (referent) & 72.9 & 1.00 & ref & ref & ref & 1.00 & ref & ref & ref \\
\hline Much more than half & 78.6 & 1.27 & 0.95 & 1.70 & 0.12 & 1.49 & 1.08 & 2.07 & 0.016 \\
\hline Around half & 78.8 & 1.37 & 1.02 & 1.84 & 0.034 & 1.48 & 1.07 & 2.04 & 0.017 \\
\hline Some but well under half & 82.2 & 1.67 & 1.25 & 2.24 & 0.001 & 1.47 & 1.06 & 2.02 & 0.019 \\
\hline None/very small & 85.9 & 2.10 & 1.46 & 3.03 & $<0.001$ & 1.50 & 1.01 & 2.24 & 0.046 \\
\hline Don't know & 57.7 & 0.52 & 0.38 & 0.71 & $<0.001$ & 0.63 & 0.45 & 0.90 & 0.010 \\
\hline \multicolumn{10}{|l|}{ Relative harm of e-cigarettes } \\
\hline Not less harmful (referent) & 56.4 & 1.00 & ref & ref & ref & 1.00 & ref & ref & ref \\
\hline Less harmful & 90.3 & 6.67 & 5.51 & 8.06 & $<0.001$ & 5.66 & 4.66 & 6.88 & $<0.001$ \\
\hline \multicolumn{10}{|l|}{ Gender } \\
\hline Male (referent) & 78.8 & 1.00 & ref & ref & ref & 1.00 & ref & ref & ref \\
\hline Female & 76.3 & 0.89 & 0.74 & 1.07 & 0.20 & 1.13 & 0.88 & 1.46 & 0.35 \\
\hline Age (years) & & & & & 0.092 & & & & 0.122 \\
\hline 18-24 (referent) & 79.9 & 1.00 & ref & ref & ref & 1.00 & ref & ref & ref \\
\hline $25-39$ & 74.3 & 0.69 & 0.47 & 1.03 & 0.066 & 0.68 & 0.40 & 1.17 & 0.16 \\
\hline $40-54$ & 78.1 & 0.87 & 0.59 & 1.28 & 0.47 & 1.01 & 0.60 & 1.72 & 0.96 \\
\hline 55 and over & 78.6 & 0.89 & 0.61 & 1.31 & 0.55 & 1.13 & 0.67 & 1.92 & 0.65 \\
\hline Annual income & & & & & $<0.001$ & & & & 0.25 \\
\hline Up to $\mathrm{f} 15000$ (referent) & 76.0 & 1.00 & ref & ref & ref & 1.00 & ref & ref & ref \\
\hline f15 001-£30 000 & 78.3 & 1.13 & 0.88 & 1.43 & 0.34 & 0.98 & 0.70 & 1.37 & 0.91 \\
\hline Over $£ 30000$ & 80.4 & 1.30 & 1.02 & 1.66 & 0.035 & 1.15 & 0.82 & 1.61 & 0.43 \\
\hline Don't know/prefer not to say & 68.6 & 0.67 & 0.49 & 0.92 & 0.012 & 0.82 & 0.54 & 1.23 & 0.33 \\
\hline
\end{tabular}

Models include 3279 observations from 1848 individuals.Bold font indicates significant associations $(p<0.05)$.

LCl, Lower Cl; UCl, Upper Cl.

know whether to support or not (figure 1). Smokers were more likely than ex-smokers to support use in smoke-free places (table 4). The more experience respondents had with e-cigarettes, the higher the odds that they supported their use in smoke-free places. Respondents who knew that only a small portion of the health risks of smoking came from nicotine were more likely to support use in smoke-free places than those who thought that nearly all the risks came from nicotine, and those who perceived e-cigarettes to be less harmful than cigarettes were more likely to support use in smoke-free places. Compared with a low income, a high income was associated with less support of use in smokefree places. Age and gender were not associated with support (table 4). There were no significant interactions between demographics and survey wave (see online supplementary table S1).

\section{DISCUSSION}

Overall, in this sample of smokers and ex-smokers, the majority did not support very restrictive e-cigarette policies, such as making e-cigarettes less available than traditional tobacco cigarettes, bans on all e-cigarette advertising and bans on their use in smoke-free places. However, support for prohibiting ecigarette use in smoke-free places increased, and in 2014, very similar proportions supported and opposed a ban. To a lesser extent, support for banning advertising also increased over the study period.

Support for policies was related to misperceptions about nicotine harms and the relative harmfulness of electronic and traditional tobacco cigarettes; those with less accurate perceptions were more likely to support more restrictive policies. Respondents with experience of e-cigarettes were more likely to support less restrictive policies than those who had never tried e-cigarettes; support appeared to be highest among regular users. Current smokers were more supportive of use of ecigarettes in smoke-free places and unrestricted advertising than ex-smokers, but similarly supportive of equal or higher availability of e-cigarettes relative to cigarettes.

This study provides an initial insight into public support of potential key regulatory approaches to e-cigarettes among 
Table 3 Association between respondent characteristics and support for advertising of e-cigarettes

\begin{tabular}{|c|c|c|c|c|c|c|c|c|c|}
\hline & \multirow{2}{*}{$\begin{array}{l}\text { Advertising should } \\
\text { be allowed (\%) }\end{array}$} & \multicolumn{4}{|c|}{ Bivariate } & \multicolumn{4}{|c|}{ Adjusted/multivariable } \\
\hline & & OR & $95 \% \mathrm{LCl}$ & $95 \%$ UCI & $p$ Value & OR & $95 \% \mathrm{LCl}$ & $95 \%$ UCI & p Value \\
\hline \multicolumn{10}{|l|}{ Wave } \\
\hline 2013 (referent) & 66.0 & 1.00 & ref & ref & ref & 1.00 & ref & ref & ref \\
\hline 2014 & 55.9 & 0.64 & 0.57 & 0.73 & $<0.001$ & 0.80 & 0.44 & 1.46 & 0.47 \\
\hline \multicolumn{10}{|l|}{ Smoking status } \\
\hline Ex-smoker (referent) & 56.1 & 1.00 & ref & ref & ref & 1.00 & ref & ref & ref \\
\hline Current smoker & 62.9 & 1.31 & 1.09 & 1.58 & 0.004 & 1.32 & 1.08 & 1.62 & 0.008 \\
\hline E-cigarette & & & & & $<0.001$ & & & & $<0.001$ \\
\hline Never tried (referent) & 52.7 & 1.00 & ref & ref & ref & 1.00 & ref & ref & ref \\
\hline Tried, not using & 60.0 & 1.35 & 1.12 & 1.62 & 0.002 & 1.23 & 1.01 & 1.50 & 0.043 \\
\hline Non-daily use & 69.9 & 1.90 & 1.57 & 2.31 & $<0.001$ & 1.44 & 1.17 & 1.79 & 0.001 \\
\hline Daily use & 78.5 & 3.14 & 2.42 & 4.07 & $<0.001$ & 2.20 & 1.65 & 2.93 & $<0.001$ \\
\hline Risks of smoking from nicotine & & & & & $<0.001$ & & & & $<0.001$ \\
\hline Nearly all (referent) & 57.1 & 1.00 & ref & ref & ref & 1.00 & ref & ref & ref \\
\hline Much more than half & 62.6 & 1.22 & 0.95 & 1.57 & 0.12 & 1.35 & 1.03 & 1.77 & 0.031 \\
\hline Around half & 60.4 & 1.11 & 0.86 & 1.43 & 0.41 & 1.18 & 0.90 & 1.54 & 0.24 \\
\hline Some but well under half & 66.4 & 1.43 & 1.12 & 1.83 & 0.005 & 1.32 & 1.01 & 1.72 & 0.042 \\
\hline None/very small & 73.6 & 1.88 & 1.39 & 2.56 & $<0.001$ & 1.49 & 1.07 & 2.06 & 0.017 \\
\hline Don't know & 42.6 & 0.59 & 0.44 & 0.80 & 0.001 & 0.70 & 0.51 & 0.96 & 0.027 \\
\hline \multicolumn{10}{|l|}{ Relative harm of e-cigarettes } \\
\hline Not less harmful (referent) & 39.6 & 1.00 & ref & ref & ref & 1.00 & ref & ref & ref \\
\hline Less harmful & 74.9 & 4.14 & 3.53 & 4.86 & $<0.001$ & 3.55 & 3.00 & 4.20 & $<0.001$ \\
\hline \multicolumn{10}{|l|}{ Gender } \\
\hline Male (referent) & 62.3 & 1.00 & ref & ref & ref & 1.00 & ref & ref & ref \\
\hline Female & 60.5 & 0.92 & 0.79 & 1.08 & 0.32 & 0.96 & 0.78 & 1.19 & 0.74 \\
\hline Age (years) & & & & & 0.012 & & & & 0.008 \\
\hline 18-24 (referent) & 63.9 & 1.00 & ref & ref & ref & 1.00 & ref & ref & ref \\
\hline $25-39$ & 56.5 & 0.73 & 0.52 & 1.01 & 0.055 & 0.67 & 0.44 & 1.02 & 0.064 \\
\hline $40-54$ & 61.6 & 0.91 & 0.66 & 1.25 & 0.56 & 1.04 & 0.69 & 1.59 & 0.84 \\
\hline 55 and over & 64.4 & 1.01 & 0.73 & 1.39 & 0.96 & 1.17 & 0.77 & 1.77 & 0.46 \\
\hline Annual income & & & & & 0.008 & & & & 0.48 \\
\hline Up to $f 15000$ (referent) & 60.9 & 1.00 & ref & ref & ref & 1.00 & ref & ref & ref \\
\hline $\mathrm{f} 15001-\mathrm{f} 30000$ & 63.8 & 1.14 & 0.92 & 1.41 & 0.24 & 1.17 & 0.89 & 1.56 & 0.27 \\
\hline Over $£ 30000$ & 62.6 & 1.08 & 0.88 & 1.33 & 0.46 & 1.14 & 0.86 & 1.51 & 0.36 \\
\hline Don't know/prefer not to say & 53.2 & 0.72 & 0.55 & 0.95 & 0.022 & 0.90 & 0.62 & 1.30 & 0.57 \\
\hline
\end{tabular}

Models include 3279 observations from 1848 individuals.Bold font indicates significant associations $(p<0.05)$.

$\mathrm{LCl}$, Lower $\mathrm{Cl}$; UCl, Upper Cl.

smokers and ex-smokers. The study findings have to be considered in the light of some limitations. To the best of our knowledge, this is the first time support for availability relative to cigarettes has been assessed. Future studies may benefit from refined questions that could break down availability into more detailed questions (eg, types of shops, by prescription); the advertising question could be improved by specifying advertising channels. Attitudes towards banning e-cigarette use are also likely to vary depending on the location (eg, outdoor vs indoor and workplaces vs restaurants ${ }^{29}$ ). It is also unlikely that the survey assessed all factors that may affect policy support; in addition to a respondent's own smoking and e-cigarette use, that of family or peers may also affect support and general political beliefs (eg, more liberal or more authoritarian) may also affect support for regulation. The sample included only smokers and ex-smokers, while never-smokers make up over $50 \%$ of the British population. ${ }^{35}$ Results for never-smokers may differ; they may, for example, report higher levels of support for restrictions $^{152728}$ and less nicotine knowledge. ${ }^{36}$
Similar to the present findings, increase in support over time for more restrictive regulations has also typically been observed with smoke-free policies. ${ }^{37}$ And for smoke-free policies, support generally increases markedly once policies are introduced. ${ }^{37} 38$

Comparison with levels of support for e-cigarette regulation found in previous surveys can only be tentative because of differences in samples and questions used. Despite possible differences in absolute levels of support however, the present and previous surveys ${ }^{12} 262729$ consistently (and unsurprisingly) find that those with e-cigarette experience are less likely to support restrictions.

The present and previous surveys also show consistency in finding that increased (inaccurate) perceived harm of e-cigarettes is associated with increased support for restrictive policies. ${ }^{12} 2627$ This is pertinent because a number of studies have shown that most people are not aware of the limited role of nicotine as a cause of smoking-related morbidity and mortality. Around half of smokers and ex-smokers from a number of countries 
Table 4 Association between respondent characteristics and support for e-cigarette use in smoke-free places

\begin{tabular}{|c|c|c|c|c|c|c|c|c|c|}
\hline & \multirow[b]{2}{*}{$\begin{array}{l}\text { Use should } \\
\text { be allowed (\%) }\end{array}$} & \multicolumn{4}{|c|}{ Bivariate } & \multicolumn{4}{|c|}{ Adjusted/multivariable } \\
\hline & & OR & $95 \%$ LCI & $95 \%$ UCI & $p$ Value & OR & $95 \% \mathrm{LCI}$ & $95 \%$ UCI & $p$ Value \\
\hline \multicolumn{10}{|l|}{ Wave } \\
\hline 2013 (referent) & 55.2 & 1.00 & ref & ref & ref & 1.00 & ref & ref & ref \\
\hline 2014 & 45.0 & 0.69 & 0.62 & 0.76 & $<0.001$ & 0.48 & 0.28 & 0.81 & 0.007 \\
\hline \multicolumn{10}{|l|}{ Smoking status } \\
\hline Ex-smoker (referent) & 38.7 & 1 & ref & ref & ref & 1 & ref & ref & ref \\
\hline Current smoker & 53.5 & 1.73 & 1.44 & 2.07 & $<0.001$ & 1.72 & 1.40 & 2.10 & $<0.001$ \\
\hline E-cigarette & & & & & $<0.001$ & & & & $<0.001$ \\
\hline Never tried (referent) & 35.0 & 1.00 & ref & ref & ref & 1.00 & ref & ref & ref \\
\hline Tried, not using & 52.4 & 1.88 & 1.57 & 2.24 & $<0.001$ & 1.89 & 1.57 & 2.29 & $<0.001$ \\
\hline Non-daily use & 65.0 & 2.90 & 2.40 & 3.51 & $<0.001$ & 2.60 & 2.13 & 3.17 & $<0.001$ \\
\hline Daily use & 73.5 & 4.50 & 3.52 & 5.76 & $<0.001$ & 4.29 & 3.29 & 5.60 & $<0.001$ \\
\hline Risks of smoking from nicotine & & & & & $<0.001$ & & & & $<0.001$ \\
\hline Nearly all (referent) & 47.9 & 1.00 & ref & ref & ref & 1.00 & ref & ref & ref \\
\hline Much more than half & 47.4 & 0.98 & 0.78 & 1.24 & 0.87 & 1.02 & 0.79 & 1.31 & 0.89 \\
\hline Around half & 46.3 & 0.88 & 0.69 & 1.11 & 0.28 & 0.87 & 0.67 & 1.12 & 0.28 \\
\hline Some but well under half & 52.2 & 1.06 & 0.83 & 1.35 & 0.64 & 0.99 & 0.76 & 1.29 & 0.93 \\
\hline None/very small & 70.1 & 1.95 & 1.46 & 2.62 & $<0.001$ & 1.74 & 1.27 & 2.39 & $<0.001$ \\
\hline Don't know & 45.2 & 0.91 & 0.68 & 1.22 & 0.55 & 1.08 & 0.78 & 1.48 & 0.65 \\
\hline \multicolumn{10}{|l|}{ Relative harm of e-cigarettes } \\
\hline Not less harmful & 34.1 & 1.00 & ref & ref & ref & 1.00 & ref & ref & ref \\
\hline Less harmful & 60.8 & 2.46 & 2.13 & 2.83 & $<0.001$ & 2.00 & 1.71 & 2.33 & $<0.001$ \\
\hline \multicolumn{10}{|l|}{ Gender } \\
\hline Male (referent) & 50.2 & 1.00 & ref & ref & ref & 1.00 & ref & ref & ref \\
\hline Female & 51.5 & 1.05 & 0.89 & 1.23 & 0.58 & 0.93 & 0.77 & 1.14 & 0.49 \\
\hline Age (years) & & & & & 0.13 & & & & 0.037 \\
\hline 18-24 (referent) & 51.6 & 1.00 & ref & ref & ref & 1.00 & ref & ref & ref \\
\hline $25-39$ & 47.4 & 0.83 & 0.60 & 1.15 & 0.26 & 0.80 & 0.54 & 1.19 & 0.27 \\
\hline $40-54$ & 51.1 & 0.96 & 0.70 & 1.31 & 0.78 & 0.97 & 0.66 & 1.41 & 0.86 \\
\hline 55 and over & 52.4 & 1.04 & 0.73 & 1.38 & 0.98 & 1.00 & 0.68 & 1.45 & 0.98 \\
\hline Annual income & & & & & 0.038 & & & & 0.073 \\
\hline Up to $\mathrm{f15} 000$ (referent) & 53.8 & 1.00 & ref & ref & ref & 1.00 & ref & ref & ref \\
\hline f15 001-f30 000 & 52.9 & 0.95 & 0.76 & 1.18 & 0.63 & 0.89 & 0.69 & 1.16 & 0.39 \\
\hline Over $£ 30000$ & 48.1 & 0.78 & 0.63 & 0.97 & 0.025 & 0.70 & 0.54 & 0.91 & 0.007 \\
\hline Don't know/prefer not to say & 46.2 & 0.73 & 0.54 & 0.98 & 0.035 & 0.75 & 0.53 & 1.06 & 0.10 \\
\hline
\end{tabular}

Models include 3279 observations from 1848 individuals.Bold font indicates significant associations $(p<0.05)$.

$\mathrm{LCl}$, Lower $\mathrm{Cl}$; UCl, Upper Cl.

erroneously thought that nicotine causes most of the smokingrelated cancers. ${ }^{39}$ Only about $15 \%$ of smokers in Sweden ${ }^{40}$ and Great Britain, ${ }^{36}$ and $<10 \%$ of the general population in Great Britain, ${ }^{36}$ knew that nicotine is responsible for a small portion of the health harms of smoking. A very similar level of knowledge about nicotine harmfulness was found in the present survey. Misperceptions of nicotine may also be behind findings that about a third of past-year smokers in England believe that using nicotine replacement therapy for more than a year would be very or quite harmful to health ${ }^{41}$ and may also be associated with increased perceived relative harm of ecigarettes. ${ }^{32}$ Misperceptions of harm are of concern because of the associations between knowledge, harm perception and policy support.

Future research may explore what harms respondents attribute to nicotine; this may be addiction as well as more direct harm to health which the measure used here and in the previous studies $^{30} 34$ did not distinguish. There are many aspects related to e-cigarette policy where evidence is still lacking. Importantly, support of different policies by groups other than smokers and ex-smokers needs to be explored; this should include those who have never smoked and anyone exposed to e-cigarette emissions at work. Further scientific evidence, for example, on the effects of e-cigarettes on air pollution, or the effects of e-cigarette advertising on smoking cessation and uptake, would allow balancing of benefits and risks of potential policies to different groups of the population.

\section{Conclusions}

Support for specific e-cigarette policies appeared to be associated with smoking status, e-cigarette use, knowledge about nicotine and perceived relative harm. Fewer restrictions on e-cigarette use in smoke-free places and advertising were more likely to be supported by current smokers, respondents with experience of e-cigarette use, respondents who perceived e-cigarettes to be less harmful, and those who were aware of the role of nicotine in smoking-related harms to health. Support for equal or higher relative availability of e-cigarettes relative to cigarettes was higher in respondents with experience of e-cigarette use, those who knew that most of the health harms of smoking are not due to nicotine, and those who perceived e-cigarettes to be less harmful than cigarettes. 


\section{What this paper adds}

- This study shows the level of support among smokers and ex-smokers in Great Britain for equal or greater availability of e-cigarettes relative to cigarettes, allowing e-cigarette advertising and use in smoke-free places.

- Support for prohibiting e-cigarette use in smoke-free places increased, and in 2014, very similar proportions (over 40\%) supported and opposed a ban. To a lesser extent, support for banning advertising also increased over the study period.

- Equal or higher availability relative to cigarettes was more likely to be supported by e-cigarette users, those who perceived e-cigarettes as less harmful than cigarettes, and those who knew that most of the health harms of smoking are not due to nicotine.

- Less restrictive policies for advertising and use in smoke-free places were more likely to be supported by smokers, e-cigarette users, those who perceived e-cigarettes to be less harmful than cigarettes and those who knew that only a small portion of the health harms of smoking are due to nicotine.

- These survey findings suggest that, in addition to smoking and e-cigarette use status, accurate knowledge about nicotine and perception of harm are determinants of policy support.

Acknowledgements The authors would like to thank the International Tobacco Control project and the Smoking Toolkit Study for survey questions.

Contributors AM conceived of the survey in collaboration with Professor Robert West and with input on the design from Dr Jamie Brown (UCL), LSB and SCH (King's). All authors contributed to the statistical analysis plan. LSB and TRP conducted the analysis with input from SCH; LSB drafted and revised the manuscript; all authors provided significant input in redrafting, contributed to and have approved the final manuscript.

Funding Cancer Research UK (C25586/A19540) funded the work on this manuscript. All authors are part of the UK Centre for Tobacco and Alcohol Studies, a UK Clinical Research Collaboration Public Health Research: Centre of Excellence. Funding from the Medical Research Council, British Heart Foundation, Cancer Research UK, Economic and Social Research Council and the National Institute for Health Research under the auspices of the UK Clinical Research Collaboration (MR/ K023195/1). The funders played no role in the study design, collection, analysis and interpretation of the data, in the writing of the manuscript and in the decision to submit this manuscript for publication.

Competing interests None declared.

Ethics approval King's College London.

Provenance and peer review Not commissioned; externally peer reviewed.

Open Access This is an Open Access article distributed in accordance with the terms of the Creative Commons Attribution (CC BY 4.0) license, which permits others to distribute, remix, adapt and build upon this work, for commercial use, provided the original work is properly cited. See: http://creativecommons.org/licenses/ by/4.0/

\section{REFERENCES}

1 McNeill A, Brose LS, Calder R, et al. E-cigarettes: an evidence update. A report commissioned by Public Health England. London: Crown Copyright, 2015.

2 Drug and Therapeutics Bulletin. Republished: Nicotine and health. BMJ 2014;349:2014.7.0264rep.

3 National Institute for Health and Care Excellence. PH45 tobacco: harm-reduction approaches to smoking. London: NICE, 2013.

4 Institute for Global Tobacco Control. Country laws regulating e-cigarettes: A policy scan. 2015. http://globaltobaccocontrol.org/e-cigarette/country-laws-regulatinge-cigarettes (accessed 19 Nov 2015).

5 Arnott D, Dockrell M, Sandford A, et al. Comprehensive smoke-free legislation in England: how advocacy won the day. Tob Control 2007;16:423-8.
6 Medicines and Healthcare Products Regulatory Agency. Licensing Procedure for Electronic Cigarettes and Other Nicotine Containing Products (NCPs) as Medicines. 2013. http://www.mhra.gov.uk/home/groups/comms-ic/documents/websiteresources/ con454361.pdf (accessed 2 Dec 2015)

7 The European Parliament and the Council of the European Union. Revision of the Tobacco Products Directive. 2014. http://ec.europa.eu/health/tobacco/docs/dir_ 201440_en.pdf (accessed 15 Apr 2015).

8 Royal Society for Public Health. Stopping smoking using other sources of nicotine. 2015. http://www.rsph.org.uk/filemanager/root/site_assets/our_work/position_ statements/rsph_smoking_positional_final.pdf (accessed 13 Nov 2015).

9 Medicines and Healthcare products Regulatory Agency. The Blue Guide. Advertising and promotion of medicines in the UK. First revision. 3rd edn. London: MHRA, 2014.

10 Committee of Advertising Practice, Broadcast Committee of Advertising Practice Consultation on the marketing of e-cigarettes. London: CAP, 2014.

11 Morrison R. E-cigarette advertising rules. E-cigarette summit. London, 2015. http://www.e-cigarette-summit.com/resources/

12 Wackowski OA, Delnevo CD. Smokers' attitudes and support for e-cigarette policies and regulation in the USA. Tob Control 2015;24:543-6.

13 Tan AS, Lee CJ, Bigman CA. Public support for selected e-cigarette regulations and associations with overall information exposure and contradictory information exposure about e-cigarettes: findings from a national survey of U.S. adults. Prev Med 2015;81:268-74.

14 Callinan JE, Clarke A, Doherty K, et al. Legislative smoking bans for reducing secondhand smoke exposure, smoking prevalence and tobacco consumption. Cochrane Database Syst Rev 2010;(4):CD005992.

15 Tan CE, Glantz SA. Association between smoke-free legislation and hospitalizations for cardiac, cerebrovascular, and respiratory diseases: a meta-analysis. Circulation 2012;126:2177-83.

16 Schober W, Szendrei K, Matzen W, et al. Use of electronic cigarettes (e-cigarettes) impairs indoor air quality and increases FeNO levels of e-cigarette consumers. Int J Hyg Environ Health 2014;217:628-37.

17 Soule EK, Maloney SF, Spindle TR, et al. Electronic cigarette use and indoor air quality in a natural setting. Tob Control 2017;26:109-12.

18 McNeill A, Etter JF, Farsalinos K, et al. A critique of a WHO-commissioned report and associated article on electronic cigarettes. Addiction 2014;109: 2128-34.

19 Ruprecht AA, De Marco C, Pozzi P, et al. Comparison between particulate matter and ultrafine particle emission by electronic and normal cigarettes in real-life conditions. Tumori 2014;100:e24-7.

20 Fernandez $E$, Ballbe $M$, Sureda $X$, et al. Particulate matter from electronic cigarettes and conventional cigarettes: a systematic review and observational study. Curr Environ Health Rep 2015;2:423-9.

21 tNational Assembly for Wales Cynulliad Cenedlaethol Cymru. Consultation Public Health (Wales) Bill. 2015. http://www.senedd.assembly.wales/mgConsultationDisplay. aspx?|D=181 (accessed 2 Dec 2015).

22 Meernik C, Baker HM, Paci K, et al. Electronic cigarettes on hospital campuses. Int J Environ Res Public Health 2016;13:pii: E87.

23 Rutherford N. Five Scottish health boards review e-cigarette policy. BBC News 2015. http://www.bbc.co.uk/news/uk-scotland-south-scotland-35150816 (accessed 3 Feb 2016).

24 Mayor of London. Transport for London Conditions of Carriage. 2016. http:// content.tfl.gov.uk/tfl-conditions-of-carriage.pdf (accessed 3 Feb 2016),

25 Tan AS, Bigman CA, Sanders-Jackson A. Sociodemographic correlates of self-reported exposure to e-cigarette communications and its association with public support for smoke-free and vape-free policies: results from a national survey of US adults. Tob Control 2015;24:574-81.

26 Kolar SK, Rogers BG, Hooper MW. Support for indoor bans on electronic cigarettes among current and former smokers. Int I Environ Res Public Health 2014;11:12174-89.

27 Mello S, Bigman CA, Sanders-Jackson A, et al. Perceived harm of secondhand electronic cigarette vapors and policy support to restrict public vaping: results from a National Survey of US adults. Nicotine Tob Res 2016;18:686-93.

28 Majeed BA, Dube SR, Sterling K, et al. Opinions about electronic cigarette use in smoke-free areas among U.S. Adults, 2012. Nicotine Tob Res 2015;17:675-81.

29 Martinez-Sanchez JM, Ballbe M, Fu M, et al. Attitudes towards electronic cigarettes regulation in indoor workplaces and selected public and private places: a population-based cross-sectional study. PLOS ONE 2014;9:e114256.

30 Brose LS, Hitchman SC, Brown J, et al. Is the use of electronic cigarettes while smoking associated with smoking cessation attempts, cessation and reduced cigarette consumption? A survey with a 1-year follow-up. Addiction 2015;110: $1160-8$.

31 Hitchman SC, Brose LS, Brown J, et al. Associations between e-cigarette type, frequency of use, and quitting smoking: findings from a longitudinal online panel survey in Great Britain. Nicotine Tob Res 2015;17:1187-94.

32 Brose LS, Brown J, Hitchman SC, et al. Perceived relative harm of electronic cigarettes over time and impact on subsequent use. A survey with 1-year and 2-year follow-ups. Drug Alcohol Depend 2015;157:106-11. 
33 Department for Work \& Pensions. Households below average income: an analysis of the income distribution 1994/95-2013/14. In: Shale J, Balchin K, Rahman J, et al. eds. National statistics report. London: Crown Copyright, 2015.

34 Fidler JA, Shahab L, West 0, et al. 'The smoking toolkit study': a national study of smoking and smoking cessation in England. BMC Public Health 2011;11: 479.

35 Office for National Statistics. Opinions and Lifestyle Survey: 2013. 2015. http://www.ons.gov.uk/peoplepopulationandcommunity/healthandsocialcare/ healthandlifeexpectancies/compendium/opinionsandlifestylesurvey/2015-03-19 (accessed 27 Apr 2016).

36 Action on Smoking and Health (ASH). Smoking still kills: protecting children, reducing inequalities. 2015. http://www.ash.org.uk/smokingstillkills (accessed 10 Feb 2016)
37 Thomson G, Wilson N, Edwards R. At the frontier of tobacco control: a brief review of public attitudes toward smoke-free outdoor places. Nicotine Tob Res 2009;11:584-90.

38 International Agency for Research on Cancer. Tobacco control, evaluating the effectiveness of smoke-free policies. Lyon, France: World Health Organization, 2009

39 Borland R, Cooper J, McNeill A, et al. Trends in beliefs about the harmfulness and use of stop-smoking medications and smokeless tobacco products among cigarettes smokers: Findings from the ITC four-country survey. Harm Reduct J 2011;8:21.

40 Wikmans T, Ramstrom L. Harm perception among Swedish daily smokers regarding nicotine, NRT-products and Swedish Snus. Tob Induc Dis 2010;8:9.

41 Black A, Beard E, Brown J, et al. Beliefs about the harms of long-term use of nicotine replacement therapy: perceptions of smokers in England. Addiction 2012;107:2037-42. 